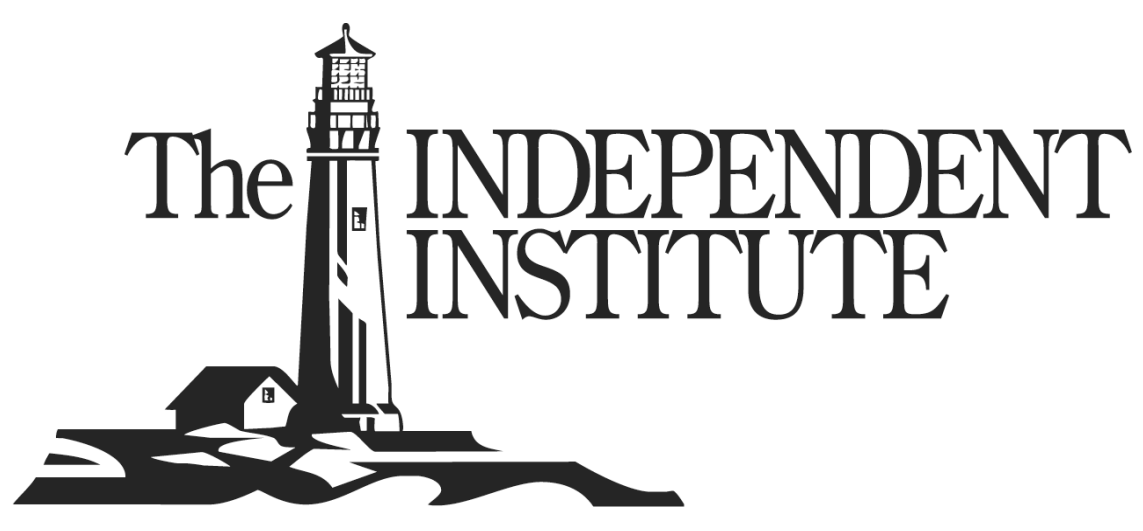

\title{
An Experimental Investigation of Hobbesian Jungles
}

\author{
Benjamin Powell \\ Department of Economics \\ San Jose State University \\ San Jose, CA 95192-0114 \\ Phone: (408) 924-1371 \\ E-mail: benjamin.powell@sjsu.edu
}

\author{
Bart J. Wilson \\ Interdisciplinary Center for Economic Science \\ George Mason University \\ 4400 University Drive, MSN 1B2 \\ Fairfax, VA 22030-4444 \\ Phone: (703) 993-4845 \\ E-mail: bwilson3@gmu.edu
}

Independent Institute Working Paper Number 61

May 23, 2005

The authors thank David Friedman, Jack Hirschleifer, Jeffery Hummel, Gordon Tullock and the participants at the Association of Private Enterprise Education conference 2004 for helpful comments and suggestions. We also thank Jeffrey Kirchner for writing the software, Matt Ryan for research assistance, and the International Foundation for Research in Experimental Economics for financial support. All errors are our own. 


\section{An Experimental Investigation of Hobbesian Jungles"}

\author{
Benjamin Powell \\ Department of Economics \\ San Jose State University \\ San Jose, CA 95192-0114 \\ Phone: (408) 924-1371 \\ E-mail: benjamin.powell@sjsu.edu
}

\author{
Bart J. Wilson \\ Interdisciplinary Center for Economic Science \\ George Mason University \\ 4400 University Drive, MSN 1B2 \\ Fairfax, VA 22030-4444 \\ Phone: (703) 993-4845 \\ E-mail: $\underline{\text { wwilson3@gmu.edu }}$
}

January, 2006

Abstract: Hobbes's state of nature serves as the analytical starting point for much of what economists have written on anarchy and the formation of government. Unfortunately little historical evidence exists about how men behaved in a "state of nature", if such a situation ever even existed. We conducted a laboratory experiment to create a Hobbesian state of nature and observe the level of economic efficiency subjects achieve. We also investigate Buchanan's conjecture that people would unanimously agree to a social contract against theft.

JEL Classifications: D60, D70, D83, C92

Keywords: Hobbesian jungle, social contract, anarchy, experimental economics

\footnotetext{
* The authors thank David Friedman, Jack Hirschleifer, Randall Holcombe, Jeffery Hummel, J. Barkley Rosser, Gordon Tullock, 3 anonymous referees, session participants at the Southern Economics Association conference 2005 and the Association of Private Enterprise Education conference 2004 for helpful comments and suggestions. We also thank Jeffrey Kirchner for writing the software, Matt Ryan for research assistance, and the International Foundation for Research in Experimental Economics for financial support. All errors are our own.
} 


\section{Introduction}

Hobbes's state of nature serves as the analytical starting point for much of what economists have written on anarchy and the formation of government. Unfortunately little historical evidence exists about how men behaved in a "state of nature", if such a situation ever even existed. We conducted this experiment to create a Hobbesian state of nature and observe the level of economic efficiency subjects achieve.

Hobbes (1651) posits that before a government was created there was a state of nature where there were no rules governing who owned which resources. Differing individual claims over scarce resources would result in violence because of the lack of rules and a single enforcer. Society would plunge into a war of all against all where the resulting life would be "nasty, brutish, and short."

Hobbes influenced much of the work by public choice economists on constitutional political economy. Tullock (1972, 1974), Bush (1974), and Buchanan (1975, 1985), all use the Hobbesian state of nature for their analytical starting point. Buchanan's analysis of the Hobbesian state of nature and the constitutional contract that would emerge continues to be particularly influential. It is discussed at the beginning of Mueller's Public Choice III graduate text (2003: 9) and is still frequently built on in the literature; Voigt (1999), Muller (2002), Murphy (2004), Kurrild-Klitgaard (2004). In another strand of the literature, the roving bandit models in McGuire and Olson (1995) and Olson (2000) are also clearly influenced by Hobbes's description of the state of nature.

The economic predictions of purely self-regarding behavior when there are no ruleenforcing institutions are quite clear. Individuals face a trade off between devoting resources to production and predation. They will steal from others when the marginal productivity of theft is 
higher than production. Resources will also be devoted to protecting one's existing resources from other's attempts at theft, but the overall amount of resources devoted to theft and protection from theft is a deadweight loss to society (Tullock: 1967).

Buchanan (1975) models the Hobbesian state of nature as a prisoners' dilemma with the Nash equilibrium in which life is "nasty, brutish, and short". Following Bush (1974), Buchanan (1975) theorizes that once property holdings were redistributed according to people's preferences and abilities for using violence in the state of nature a "natural distribution" of property would emerge. The natural distribution would remain inefficient because of the continued use of resources for theft and protection. All people could be better off once the natural distribution was reached by moving from the bottom right corner to the upper left in the prisoner's dilemma.

Buchanan (1975) conjectures that all people would agree to a constitutional contract that prohibits theft and protects property. He recognizes that without an enforcement institution people would continue to have an incentive to defect from the agreement and society would plunge back into the jungle. Buchanan concludes that people would all be better off if there was an enforcer to make them abide by the agreement, so they would conceptually agree to form a limited government $(1975,1985)$.

Although analytically appealing, little historical evidence exists about how humans behave in an institutionless state of nature. As Tullock notes, "Hobbes's 'war of all against all' was not part of human history" and that "Insofar as we can tell man developed from an ape which was already social. In other words, our predecessors lived in small bands whose social coherence depended to a considerable extent upon inherited behavior patterns" (1974: 9). In many historical cases where no single government existed, spontaneous human interaction often 
produced a set of property rights and a voluntary legal code. ${ }^{1}$ Since there is a lack of historical evidence of how people might behave in a Hobbesian state of nature we create a laboratory environment to observe individuals' behavior in such a setting.

There is reason to doubt that people would behave the way Hobbes predicts in the state of nature. Buchanan himself writes,

"Nowhere in the analysis am I denying the possible existence of internal behavioral constraints that may serve to inhibit man's seizing stocks of goods produced by others or invading physical domain initially inhabited by others. I remain agnostic on this as on many other aspects of human nature. My emphasis here is that such constraints, if they do exist, are over and beyond those normally introduced in economics behavioral models" (1975: 82).

Since Buchanan's original writing many experiments have tested the extent of subject's "otherregarding behavior." A plethora of previous work has found that subjects cooperate more in prisoners' dilemma games, sequential moves requiring trust, social dilemmas, and voluntary contribution mechanisms for public goods than game theory would predict (see, e.g., Kelley and Stahelski, 1970; Andreoni and Miller, 1993; Camerer and Weigelt, 1988; Berg et al., 1994; Dawes, 1980; and Isaac and Walker, 1984). ${ }^{2}$

In the Hobbesian framework there is even more reason to be optimistic. Humans tend to be non-cooperative in market exchange while simultaneously cooperative in other more personal, social situations. Non-cooperation in a Hobbesian world is more than a failure to produce the optimal level of public goods. It clearly involves taking the property of another person. Even with the anonymity of the experiment, other-regarding behavior in personal social exchange can limit the amount of theft that occurs even without enforcing institutions. As Smith observes

\footnotetext{
${ }^{1}$ See Friedman (1979), Benson (1988, 1990) Anderson and Hill (1979).

${ }^{2}$ For summaries and collections of work, see Camerer (2003) and Smith (2000).
} 
“property rights predate nation states... In what sense are such rights 'natural?' The answer, I think, is to be found in the universality, spontaneity, and evolutionary fitness value of reciprocity behavior" (1998: 3). Some of the behavioral traits that limited fighting within tribes and other social interaction prior to nation states are likely to limit the theft and inefficiency in this Hobbesian jungle experiment.

Durham et al. (1998) conduct an experiment that is related to ours in which they examine the "Paradox of Power" (Hirshleifer, 1991), the observation that weaker parties improve their position relative to stronger opponent because the weaker subject has a stronger motive to fight harder. They find that their experimental observations are clearly more supportive of the Nash predictions than cooperative ones. A fundamental difference between their framework and our design is that the earning functions in our experiment are independent for each subject; there is no payoff for an individual from other's productive effort. This feature of our design induces even more self-regarding behavior and biases the observations to a more nasty and brutish outcome. Their subjects also interact in pairs whereas our societies are comprised of six interacting individuals.

Similar to Durham et al. (1998), Carter and Anderton (2001) also investigate pairs of subjects who alternate between two types of roles, first-movers who can be productive and/or engage in defense and second-movers who can be productive and/or engage in offense to appropriate endowments of the first-movers. The second-movers observe the decisions of the first-movers before making their decisions. They find that increasing the relative effectiveness of predation against defense leads to changes in predation as predicted by Grossman and Kim (1996). Duffy and Kim (2005) complement these works by increasing the size of the societies from pairs to ten individuals who can choose to be either a producer or a plunderer, but each 
person can only be one or the other. Their producers decide how to divide their endowment between income production and defense against plunder, and plunderers must invest all their resources into plundering. The main contribution of Duffy and Kim (2005) is a treatment in which an eleventh person, a dictator, chooses the level of defense for all producers to deter plunder. All producers share equally in the production that remains after plundering, and all producers share equally in the production appropriated from the producers. They find (a) that without dictators the experimental economies approach the Nash equilibrium of their anarchy model and (b) that dictators lead all of the individuals to become producers instead of plunderers, thereby achieving a Pareto superior outcome.

In our experimental societies, each of the six individuals can choose how much, if any, of their productive endowment to invest in offense and/or defense. They are not assigned one role or the other. Moreover, our experiment is essentially conducted in continuous time, i.e., defensive decisions do not necessarily precede offensive ones and offensive choices do not necessarily follow defensive decisions. Actions can occur at any time. Each subject also has just one shot with their "life." There are no rounds in which subjects repeatedly face the same decisions. A subject can die in the sense that once all of their productive endowment is taken, they earn no more. Our individuals are also not compartmentalized, exogenously or endogenously, as either pure producers or pure plunderers; they can choose the degree to which they wish to allocate productive units to offense and defense and can change these allocations throughout the experiment. Lastly, in our experimental economies, there is no social component to consumption; all production is privately consumed. In sum, our Hobbesian jungle is very much unstructured as one would imagine a pre-state world would be. 


\section{Experimental Design and Procedures}

For this experiment we recruited subjects from the undergraduate population at large at George Mason University. Students were brought into the lab and seated at a visually isolated computer terminal where they interacted anonymously with other participants. Subjects received electronic instructions about how to participate in the experiment (see appendix 1). Each session had 6 participants who only participated in a single session. To attempt to mitigate end game effects of a necessarily finite experiment, the subjects were recruited for an experiment that could last up to ninety-minutes, but the actual experimental interaction time was left undisclosed. This simulates a Hobbesian jungle in that no individual knows with certainty how long their life will last, and we wished to avoid artificially imposing end game effects. The actual experiment lasted 25 minutes after approximately 10-15 minutes of instructions.

Subjects received $\$ 5$ for showing up on time in addition to their salient earnings. Initial endowments to the subjects are in a unit $x$ that earns US\$0.0014 every second that it is allocated as an income generating unit. A subject's screen updates his or her total earnings in real time. The differing endowments of $x$ are: 19, 21, 23, 25, 27, and 29 with the subject scoring highest on a general knowledge quiz receiving the endowment of 29 , second highest 27 and so forth (see appendix 2 for the quiz). Speed of finishing the quiz breaks any ties. The quiz simulates Lockean homesteaded property in the state of nature. Previous experimental work indicates that this procedure generates a sense of an earned property right (see Hoffman and Spitzer, 1982, 1985; Hoffman et al., 1994; and Cherry et al., 2002). Even with no formal title or governing institution it is clear that individuals who come to interact in the state of nature must posses something prior to their interaction and their possessions and wealth will likely differ based on their abilities and prior experience. 
The initial endowments of $x$ can be converted into units of either offense $o$ or defense $d$ once the experiment begins. Offensive units could be used to attempt to take units of $x$ from another subject while defensive units could be used to attempt to protect a subject's existing units of $x$. The rationale for having differing units for defense and offense is that, while some goods may be useful for both, in many cases goods are not equally well suited for both activities. For example, a wall or a lock provides a form of defense that is not easily used to steal from someone else, and a siege tower or lock pick set is not very useful for defending existing property.

Units of $d$ or $o$ do not earn money. The opportunity cost of holding units of defense and offense is the rate of return they could earn if they are instead units of $x$. To incorporate a transactions cost of moving productive assets into either offensive or defensive use there is a 10second conversion time from when a subject decided to convert a unit of $x$ into offense or defense before the unit is available. During the conversion time the unit does not earn money. All units can be converted or reconverted to any other type throughout the experiment with a 10second delay.

Subjects could use the units of offense to "take" $x$ from another subject. The probability that an attempt to plunder is successful is determined by the number of offensive units $o_{a}$ the attacker $a$ has compared to the number of defensive units $d_{t}$ the target $t$ under attack has. Specifically, the success rate for attacker is $\frac{o_{a}}{o_{a}+d_{t}}$. After any attempt at using force units are not available for use for 20 seconds while they "recuperate" from battle.

To capture the essence of Buchanan's (1975) constitutional contract, after five minutes a poll is broadcast to all the subjects asking them, "Do you agree not to take from another?" If everyone agrees to refrain from taking and actually refrains from taking after the contract is 
adopted, the poll is not broadcast again. ${ }^{3}$ If the poll fails to get unanimity or fighting re-emerges, it is rebroadcast every five minutes until either it is accepted and violence ceases or until the experiment ends. The poll results are broadcast to all subjects so they could observe which other people (i.e. "person 2") agree or do not agree.

In addition to poll responses, individual subject holdings of $x, o$, and $d$ are publicly observable to all participants throughout the experiment. All attempts at plunder and the result of the attempts are broadcast to all participants. All information is public because most visions of a Hobbesian jungle involve individuals interacting locally and regionally so they would likely come to learn much of this information. Individual subject identities remain anonymous at all times through the use of computers.

If all units are held in units of $x$ by all subjects throughout the entire experiment the average payout to subjects is $\$ 50.40$ per person, i.e., each subject could on average earn $\$ 2.016$ per minute.

Admittedly, not imposing much order in our experiment comes at the cost of identifying a well-defined Nash equilibrium prediction of a precisely structured game. But a formal gametheoretic test of a model of Nash behavior is not our objective. As valuable as these tests are, imposing a formal model and the required structure to our solve for an equilibrium in Hobbesian anarchy would assume away much of what we wish to observe: the workings of a lawless and disorderly Hobbesian jungle with opportunities to agree to a social contract. Replacing the phenomenon of Hobbesian anarchy with an analytically solvable model is also perhaps oxymoronic. It also assumes a causality and a concealed mechanism that we do not wish to

\footnotetext{
${ }^{3}$ In the event that a subject lost all of his units he was still allowed to vote on the constitutional contract. However, out of a total of 31 polls or 186 individual votes this occurred 29 times. None of these 29 cases ever caused a poll to be rejected that would have otherwise been accepted unanimously by the remaining subjects.
} 
compel here. We are setting out in this laboratory experiment to observe a simple phenomenon as a basis for understanding anarchy in more complex situations.

There are, however, some outcomes that we do not expect to observe, such as all subjects devoting all units only to defense. In such a situation, any individual can move some of his units of defense into the earning asset $x$ without risk since the other subjects do not have any units of offense with which to attack. The fully efficient outcome of holding all units in the earning asset $x$ is also unsustainable. If all subjects maintain all units in $x$, then moving one unit into $o$ to take $x$ from other subjects (every 20 seconds) would be successful 100 percent of the time. Finally, one extreme condition is potentially sustainable — all people holding all units in $o$. A deviation to move one unit into the earning asset $x$ would be immediately taken with 100 percent certainty, and moving a single unit into $d$ is only a weak deviation since it would not be defending anything.

As limiting cases, perfect efficiency and pure amorphy serve as our two benchmarks because they have been so important in political philosophy for the past 350 years. Hobbes (1651), and more recently economists such as Buchanan (1975) and Olson (2000) predict an extremely inefficient outcome while social theorist such as Proudhon (1994) and utopians predict outcomes closer to pure efficiency. We design our economic environment and institution so that there is no single stage game; the setting is dynamic. Our experiment is exploratory in nature as we seek to identify a set of stylized facts in Hobbesian jungles upon which future work can be built (Smith, 1982). Basically, we know precious little about the workings of a Hobbesian jungle in the laboratory, and this experiment is part of a first step at establishing a baseline for understanding the evolution of roaming tribes to organized states, starting with the behavior of 
individuals. The results reported in Section IV will answer the following questions on the stylized facts we observed: ${ }^{4}$

- Are experimental Hobbesian jungles on average approximately $10 \%, 40 \%$, or $70 \%$ efficient, where efficiency is defined as the realized earnings divided by the maximum possible earnings?

- Is the range of observed efficiencies across groups narrow or large?

- Are all resources devoted to offense and/or defense about $5 \%, 25 \%$, or $50 \%$ of the time?

- Are about $0 \%, 50 \%$, or $100 \%$ of Buchanan's non-binding social contracts unanimously adopted?

- Do unanimously adopted social contracts change the course of an economy or not?

- Are the lives of none, one-third, or two-thirds of the individuals cut short? Is this a consistent or erratic observation?

- Is there negative, positive, or no correlation between the number of attempts at plunder and efficiency? Between the number of adopted constitutional contracts and efficiency?

To summarize, out of the general literature on the state of nature emerge the following benchmarks:

A) Subjects will devote large amounts of resources to plunder and defense. The outcome will be extremely economically inefficient (in Hobbesian terms: nasty, brutish, and short).

An alternative benchmark offered by some utopian anarchists (Prodhound 1994) is that there is no need for any institutions of governance and enforcement:

A2) Subjects will cooperate and not plunder each others property. No resources will be wasted on predation and defense.

B) When offered a non-binding social contract to agree not to steal from one another, they will all choose to accept the social contract since it is a Pareto improvement.

\footnotetext{
${ }^{4}$ Obviously we did not know beforehand what we would observe, which is why we ran the experiment. To garner an appreciation for the possibilities of what could have happened but did not, we invite the readers to circle their answers to these questions before proceeding to the results.
} 
C) After agreeing to the social contract, subjects will defect because there is no government to enforce the agreement. Society will plunge back into the inefficient state.

\section{Experimental Results}

We conducted 8 sessions of 6 subjects. ${ }^{5}$ Figure 1 displays the number of units allocated to earning, offense and defense by session. At any period, each shaded area represents the total number units allocated to earnings, offense, and defense. ${ }^{6}$ The figure also reports the results of the social contract poll and the number of individuals who were eliminated by other people. The data reject hypothesis B, and A2. Six individuals almost never agree to a Buchanan style social contract (B). Subjects clearly do not achieve the utopian result of pure cooperation (A2), and only one of the eight sessions was tremendously inefficient as predicted by Buchanan, Olson and Hobbes (A).

Life with no institutions of governance is neither "nasty, brutish, and short" nor perfectly harmonious. Economic efficiency averages $42.9 \%$ over all eight sessions, or US\$20.86 per subject. No individual session achieves utopian results (the best is $70.6 \%$ ) and only one approaches a Hobbesian world (the worst is $13.7 \%$ ).

Despite relatively high levels of efficiency compared to a Hobbesian prediction, some individual subjects do have their experimental life cut short. In seven of the eight sessions at least two subjects have all or nearly all of their units taken from them. Twelve subjects ended the experiment with no units at all, and two other people only had one and three units remaining. For all intents and purposes, they are eliminated from the experiment in that they protected those

\footnotetext{
${ }^{5}$ With such an unstructured experiment, we decided to run 8 independent groups of subjects as compared to the 3-5 normally conducted in experimental studies.

${ }^{6}$ The total number of units falls below $144(=19+21+\ldots+29)$ when subjects are transferring units into $x, o$, and $d$.
} 
units in offense so as to not allow them to be taken. Only in one session do all the individuals "survive" to the end of the experiment.

\section{INSERT FIGURE 1 ABOUT HERE}

Our experiment also allows us to examine the occurrence of a breakdown of anarchy that Hirshleifer (1995) called "amorphy," where no resources are devoted to productive activity - a truly Hobbesian result. Duffy and Kim (2005) find that, in 3 of their 90 rounds of decision making in their no government treatment, the amorphic result occurs despite the fact that an individual's best reply if all others are not producing is to devote some resources to production. We observe the amorphic result only briefly in sessions 5 and 7 . Since our experiment is implemented in real time there are many more opportunities for anarchy to break down and the amorphic result to emerge. A real time experiment also permits us to observe how long the amorphic result lasts. The longest an amorphic result lasted was 53 seconds in session 7 . Overall it emerged on 4 separate occasions for a total of 94 seconds in session 5 and 2 separate incidences for a total of 87 seconds in session 7. Anarchy does not completely break down to the Hobbesian amorphic result or even approach it in the vast majority of our sessions. Out of a total time of 11,579 seconds in our 8 experimental sessions, anarchy only leads to the amorphic result a total of 181 seconds in 2 of the 8 sessions, or $1.6 \%$ of the time.

Our results on the level of efficiency and the lack of complete breakdown are significant given the Hobbesian influence on the political economy literature. By running our experiment in real time, leaving the subject actions as open ended as possible, and not allowing communication and groups to form we created an experimental environment in line with what Hobbes envisioned. Yet our overall results are striking, though clearly not utopian, because of the modest level of overall efficiency and the rarity of complete amorphic breakdown. 
Table 1 contains summary statistics for each of the 8 sessions. We first notice that that the total number of plunder attempts is not correlated with efficiency. Over the 8 sessions the average number of plunders attempted is 289 . The maximum possible number of takes if each subject attempted one take every 20 seconds is 450 . Recall that there is no marginal cost (other than possible reputation with other anonymous participants) associated with attempting to take a unit from another person. The marginal costs arise from having offensive units, not from using them. As long as a subject held at least one offensive unit there is no cost associated with attempting to use it every twenty seconds. Overall, the total number of attempted takes is relatively stable across the sessions ranging from a high of 286 to a low of $226 .^{7}$ There is seemingly no relationship between the variation in the number of attempted takes and the level of economic efficiency achieved in each session. Sessions 5 and 7 had the two lowest numbers of plunder attempts yet they achieved two of the three lowest levels of efficiency. The other session with extremely low efficiency has the highest number of plunder attempts. Yet session 3, which achieves more than 70 percent efficiency, is projected to have 325 plunder attempts if it reached full term.

\section{INSERT TABLE 1 ABOUT HERE}

Early arms races do seem to predict the overall efficiency that a session will achieve. When there is heavier investment in offense and defense in the first five minutes of the experiment efficiency tends to be lower. In the three sessions where efficiency is below 30 percent, on average 65 out of 144 total units are held in offensive or defensive units over the first 5 minutes of the experiment, while in the three sessions with over 50 percent efficiency only 44 units of offense or defense are held over the first five minutes on average (see Figure 2). The

\footnotetext{
${ }^{7}$ The actual observed high is 286 in session 6 however, there were 271 attempted takes in session 3 which was ended early. Had it finished as scheduled, the projected number of attempted takes is 325 .
} 
two sessions with efficiency in the 40 percent range provide an intermediate case where 48 units of offense or defense were held over the first 5 minutes.

\section{INSERT FIGURE 2 ABOUT HERE}

In general an early arms raced predicts a less efficient outcome but session 1 is a notable exception. It is fifty percent efficient, yet over the first five minutes more than 59 units are dedicated to offense or defense on average. This session is unique because it has far more total "yes" votes for the social contract over the 4 polls than any other session. It is also the only session where any single poll ever passed unanimously 6-0 (results of each individual poll are reported at the top of each panel in Figure 1). Fighting reemerges only 13 seconds after the social contract is unanimously agreed to, as Buchanan (1975) predicts. However, in this one case, despite the reemergence of fighting, efficiency does improve substantially until it levels off after the next social contract poll that fails to garner unanimous consent. Since only one of our 31 constitutional polls passes unanimously there is not enough data to draw conclusions about either Benchmark C (subjects will always defect) or the implications for efficiency after a nonbinding poll passes.

We also analyze the determinants of how many yes votes the social contract poll receives with a simple OLS regression:

$$
\text { YesVotes }_{t}=\alpha+\beta_{1} \text { AvgEff }_{t}+\beta_{2}(O / D)_{t}+\beta_{3} \text { PlndAttmpt }_{t}+\sum_{j=2}^{4} \delta_{j} D_{j t}+\varepsilon_{i t}
$$

Where the number of YesVotes is $_{t}$ the number yes votes on social contract $t=1, \ldots, 4, A v g E f f$ is the average level of efficiency in the previous 5 minutes of the experiment, $(O / D)$ is the ratio of offensive to defensive units at the time of the contract, and PlndAttmpt is the number of plunder attempts over the previous five minutes. We also included dummy variables $D_{j t}$ for whether the poll is the $j^{\text {th }}$ one offered. Table 2 reports that none of these variable are even close to being 
statistically significant. In our experiment, the social contract poll is essentially a form of "cheap talk" between the subjects because it is non-binding, and the estimates in Table 2 confirm this. INSERT TABLE TWO HERE.

Our constitutional contract closely matches what Buchanan (1975) modeled as the first attempted step out of the Hobbesian jungle. Unfortunately it is hard to draw too strong of a conclusion from this feature of the experiment since only one social contract was agreed to. This is clearly an area for further research. Specifically, treatments that allow for a binding contract enforced externally by experimental design would further test Buchanan's analysis as to whether individuals in the state of nature would unanimously agree to form a limited government. Further treatments could also examine whether they would agree to contracts with a Leviathan government that takes many of their resources but stops infighting and what would happen with endogenous enforcement of the infighting by an active government subject.

We now turn our attention to the determinants of individual performance of total earnings in US dollars (TotalEarnings) and the total number of units (TotalUnits) at the end of the session (period 1500). For the quantitative analysis we employ a linear mixed-effects model for repeated measures on subjects. The initial endowment of units (Endow), the early amount of offense $(O 300)$ and defense (D300) at period 300, and the number of plunder attempts (PlndAttmpt) are modeled as fixed effects, while the 8 independent sessions are modeled as random effects $e_{i}$. Specifically, we estimate the model

$$
Y_{i j}=\alpha+e_{i}+\beta_{1} \text { Endow }_{i j}+\beta_{2} O_{i j}+\beta_{3} D_{i j}+\text { PlndAttmpt }_{i j}+\varepsilon_{i j}
$$

where $e_{i} \sim N\left(0, \sigma_{1}^{2}\right)$ and $\varepsilon_{i j} \sim N\left(0, \sigma_{2, i}^{2}\right)$. The sessions are indexed by $i=1, \ldots, 8$ and the repeated measures of subjects within are indexed by $j=1, \ldots, 6$. We accommodate heteroskedastic errors by session when estimating the model via maximum likelihood. Table 3 reports our results. 


\section{INSERT TABLE 3 ABOUT HERE}

We find that two effects determine the total earnings of individuals in our experiment, their endowment and the number of attempts at plunder. Each endowed unit of $x$ at the beginning of the session generates $\hat{\beta}_{1}=50 \phi$ for a subject. Hence, the difference in total earnings between the best and worst performers on the quiz is $\$ 5=(29-19) \times 0.50$. The other significant way to increase your earnings is to plunder and each attempt generates $\hat{\beta}_{4}=24 \notin$ over the course of the session. This is equivalent to a maximum of $72 \varnothing$ per minute if a subject attempt theft as frequently as possible. Early investment in offense and defense does not explain an individual subject's earnings ( $p$-values $=0.4367$ and 0.4763 , respectively).

The estimates of the model for the total number of units at the end of the session tell an interesting story. While the initial endowment of units has some effect on earnings, it does not explain how many units a subject has at the end of the session ( $p$-value $=0.1141)$. Early investment in offense also does not appear to explain ending balances of total units $(p$-value $=$ 0.8498). However, early investment in defense is highly significant and very important. Every unit of defense in period 300 results in $\hat{\beta}_{3}=1.71$ units at the end of experiment ( $p$-value $=$ 0.0007), i.e., a unit in defense in period 300 is still present at the end of the experiment, plus .71 of another unit. In other words, an investment in strong defense early on is essential for survival. Figure 3 confirms this with representative plots of the allocation of units for four eliminated individuals. Succinctly, a dearth of defense dooms. Person 3 in session 5 heavily invests in offense early in the experiment and soon as he moves the units into earnings without any in defense, they are steadily picked off in just two minutes. Table 3 also reports that each attempt at plunder is important for accumulating units, generating about a half of a unit at the end of the session $\left(\hat{\beta}_{4}=0.53, p\right.$-value $\left.<0.0001\right)$. 


\section{$\underline{\text { VI. Conclusion }}$}

The Hobbesian vision of society without a state has been an extremely influential one. Our experiment creates an institutionless state of nature in which we observe how real people interact. We find that, although far from utopian, there are much higher levels of cooperation in Hobbesian anarchy than what many have alleged. In sum, we find the following:

- Our experimental Hobbesian jungles are $42.9 \%$ efficient on average, ranging from a low of $13.7 \%$ to a high of $70.6 \% .^{8}$

- All resources in a group are devoted to the unproductive use of offense and defense a mere $1.6 \%$ of the time.

- Only 1 out of 31 constitutional contracts is unanimously adopted and plundering continues shortly thereafter.

- Consistently, one-third of the individuals' lives are cut short.

- There is no correlation between the number of attempts at plunder and efficiency. With only one non-binding social contract adopted there not enough data to assess their effect on efficiency.

Historical cases of anarchy are likely to achieve higher levels of efficiency than this experiment. In particular this experiment does not allow for endogenous group formation with the ability to exclude. Tullock (1985) shows that cooperative outcomes in prisoners' dilemma games are much more likely with the ability to select partners and exclude others.

Economists have debated the ability of private companies to provide both defense and law in a competitive environment. ${ }^{9} \quad$ This experiment does not directly address this form of anarchy with governance. Our experiment attempts to establish a likely baseline of the minimum

\footnotetext{
${ }^{8} \mathrm{We}$ intriguingly note that one anonymous referee interprets the efficiency of the sessions as "surprisingly high" and another as "quite nasty".

${ }^{9}$ See: Rothbard (1973), Nozick (1974), Friedman (1989, 1994), Benson (1990, 1998), Cowen (1992), Sutter (1995), Barnett (1998), Cowen and Sutter (1999), Stringham (1999), Caplan and Stringham (2003).
} 
efficiency that anarchy with no institutions of any sort will achieve. It may be possible to achieve even higher levels of efficiency with exclusion, groups of individuals, and voluntary coordination on the provision of defense. Other interesting features include endowing individuals with comparative advantages in production so that they may trade units for the defensive and offensive skills of individuals so comparatively endowed.

Our findings indicate that both Buchanan (1975) and Olson (2000) may too pessimistically assume the baseline efficiency in the state of nature, though at least we find one session that is highly inefficient. ${ }^{10}$ It would be interesting for future work to follow Duffy and Kim (2005) in investigating Olson's move from roving bandits (Hobbesian Anarchy) to a stationary bandit of a government. How would an economy with a government that could engage in harm to its subjects compare in terms of efficiency to the economies observed here? ${ }^{11}$ Future social contract experiments could explore the effects of externally enforced binding social contracts and the effects on subject welfare and efficiency when enforcement power is given to an individual subject autocrat with the ability to plunder for himself. It would also be fruitful to explore how the ability to trade two commodities and how a comparative advantage in coercion might affect the level of violence and hence efficiency. Trade may reduce interpersonal frictions, particularly given its positive sum nature. Adding trade is also consistent with Buchanan (1975) and would provide another hypothesis that trade in goods will not occur until after the constitutional contract that establishes rights has been adopted. Although not precisely a Hobbesian jungle, other recent research (Horan et al 2005) has shown how trade could have been an important reason for the rise of humans and the extinction of Neanderthals. Clearly,

\footnotetext{
${ }^{10}$ A second problem with both Buchanan and Olson is that even with pessimistic assumptions about the state of nature, if those same immoral individuals are analyzed as the rulers of the government welfare is not necessarily improved. See Powell and Coyne (2003) for this argument.

${ }^{11}$ For some of the worst cases in the naturally occurring world, see Rummel (1994).
} 
incorporating trade into a Hobbesian jungle experiment is another interesting area for future research. 


\section{Session 1}

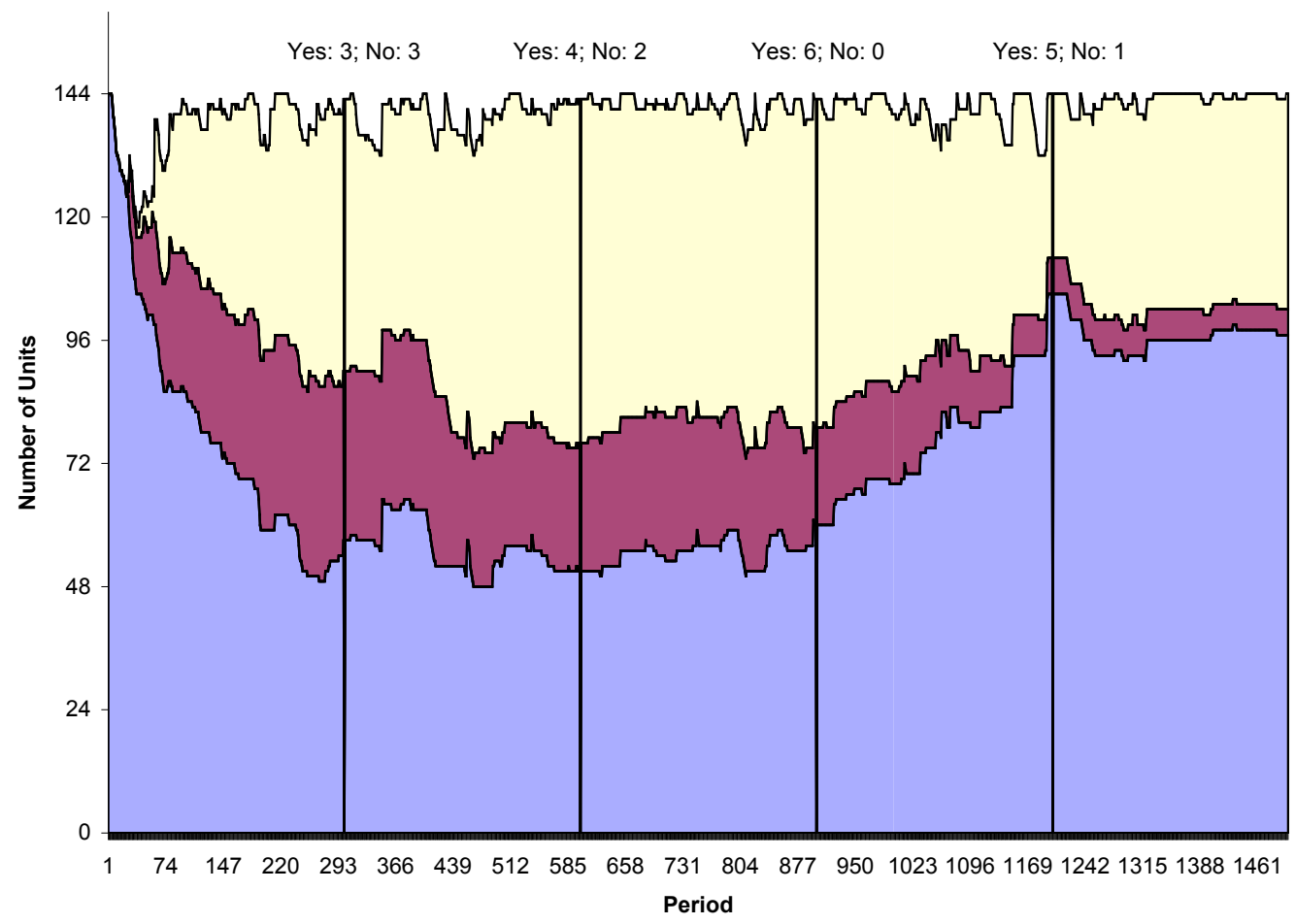

$\square$ Defense Units $\square$ Offense Units $\square$ Earning Units

Efficiency: $50.1 \%$

Persons eliminated: 2

Session 2

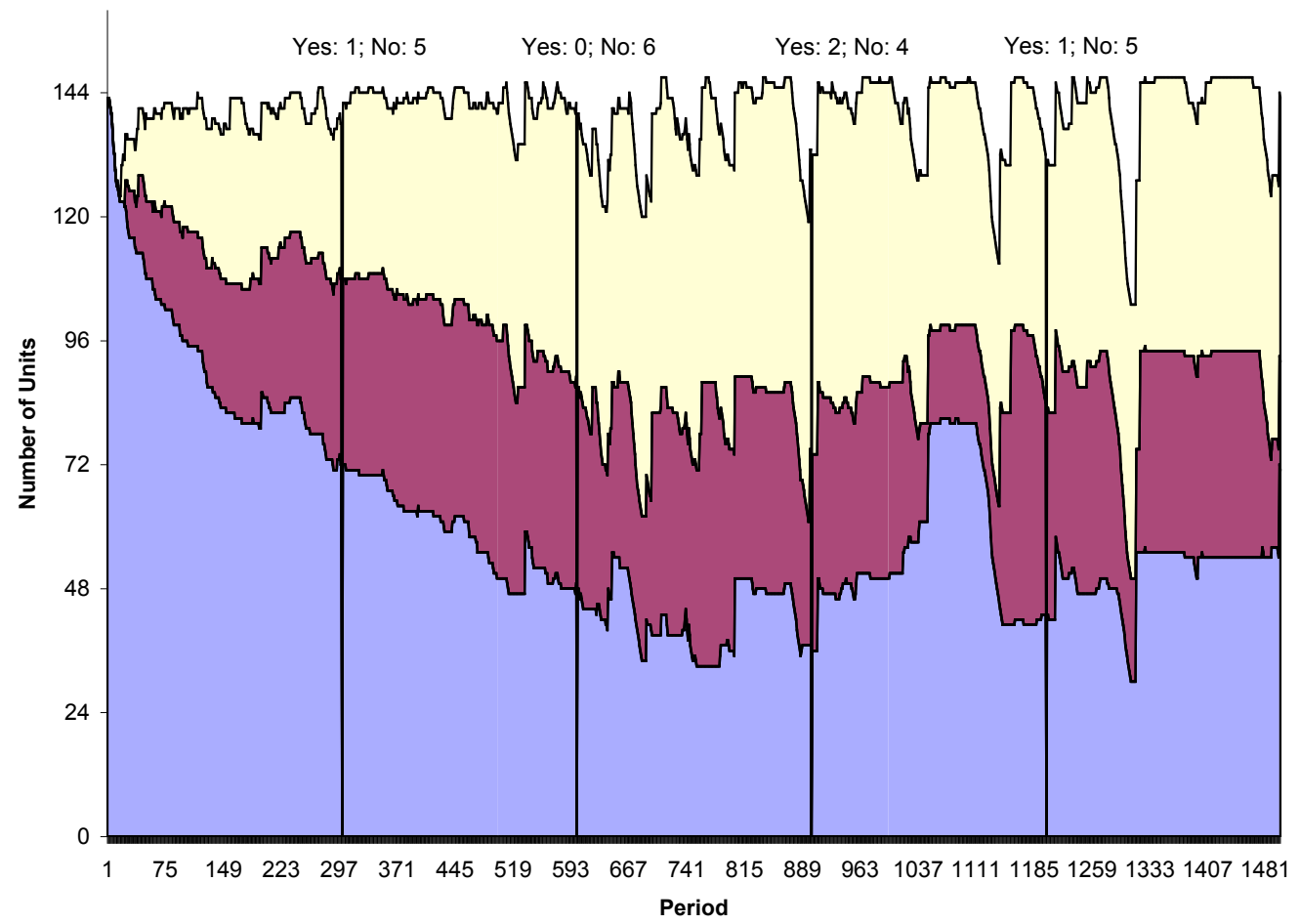

$\square$ Defense Units

$\square$ Offense Units

$\square$ Earning Units

Efficiency: $41.8 \%$

Persons eliminated: 2

Figure 1a. Allocation of Units 
Session 3

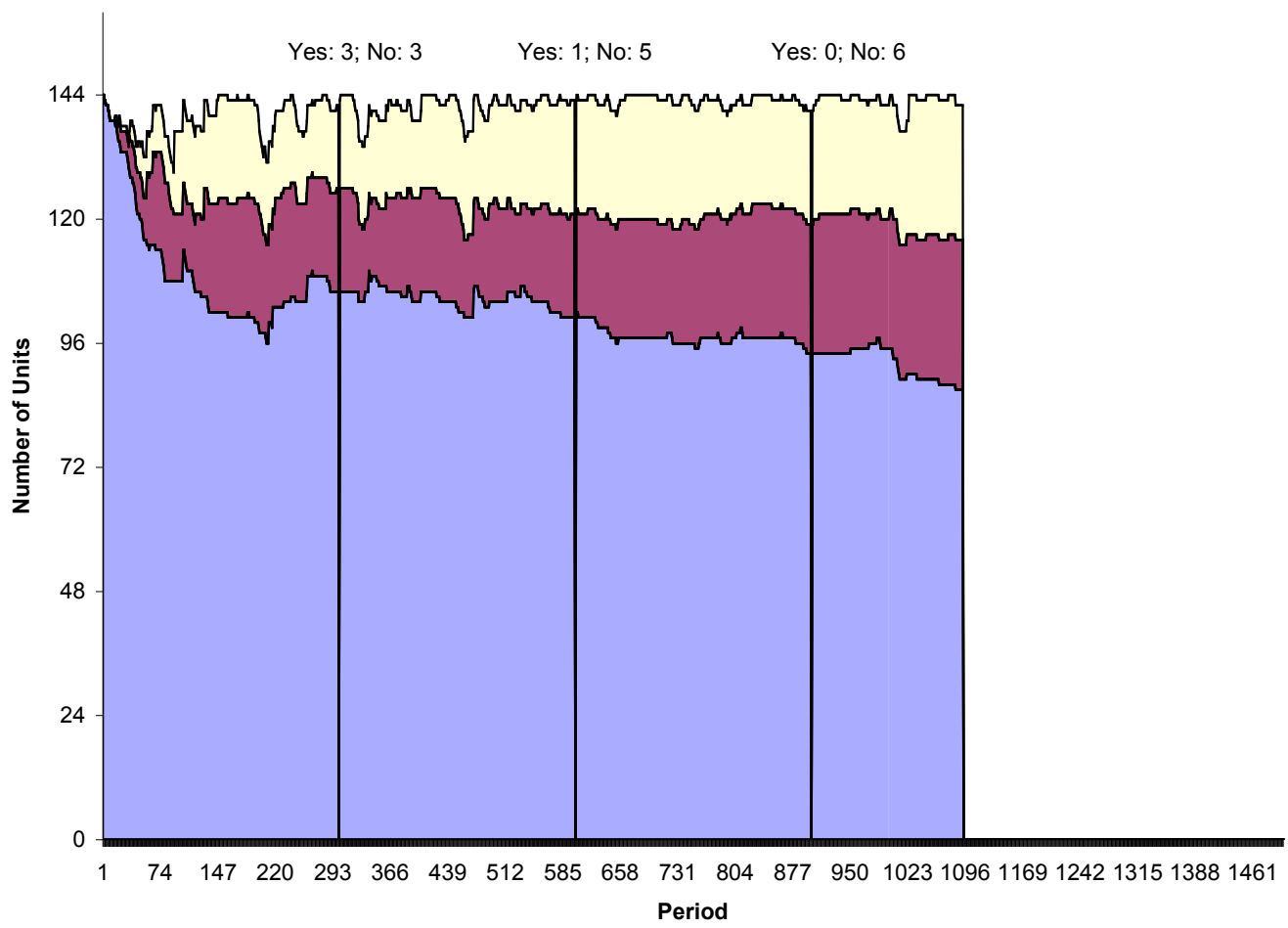

口Defense Units 口Offense Units $\square$ Earning Units

Efficiency: $70.6 \%$

Persons eliminated: 2

This session was terminated early due to a computer error.

Session 4

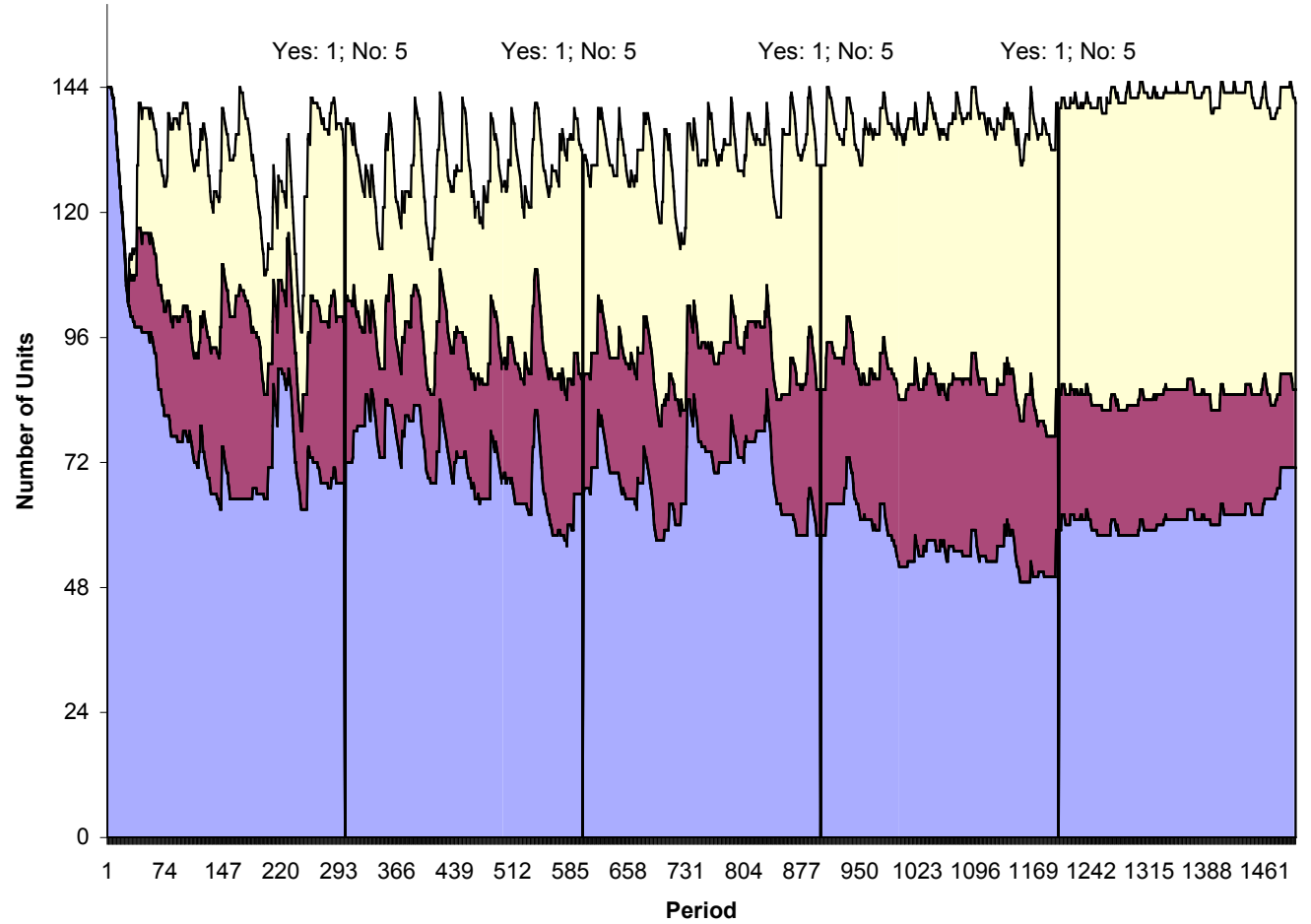

$\square$ Defense Units $\square$ Offense Units $\square$ Earning Units

Efficiency: $47.0 \%$

Persons eliminated: 2

Figure 1b. Allocation of Units 
Session 5

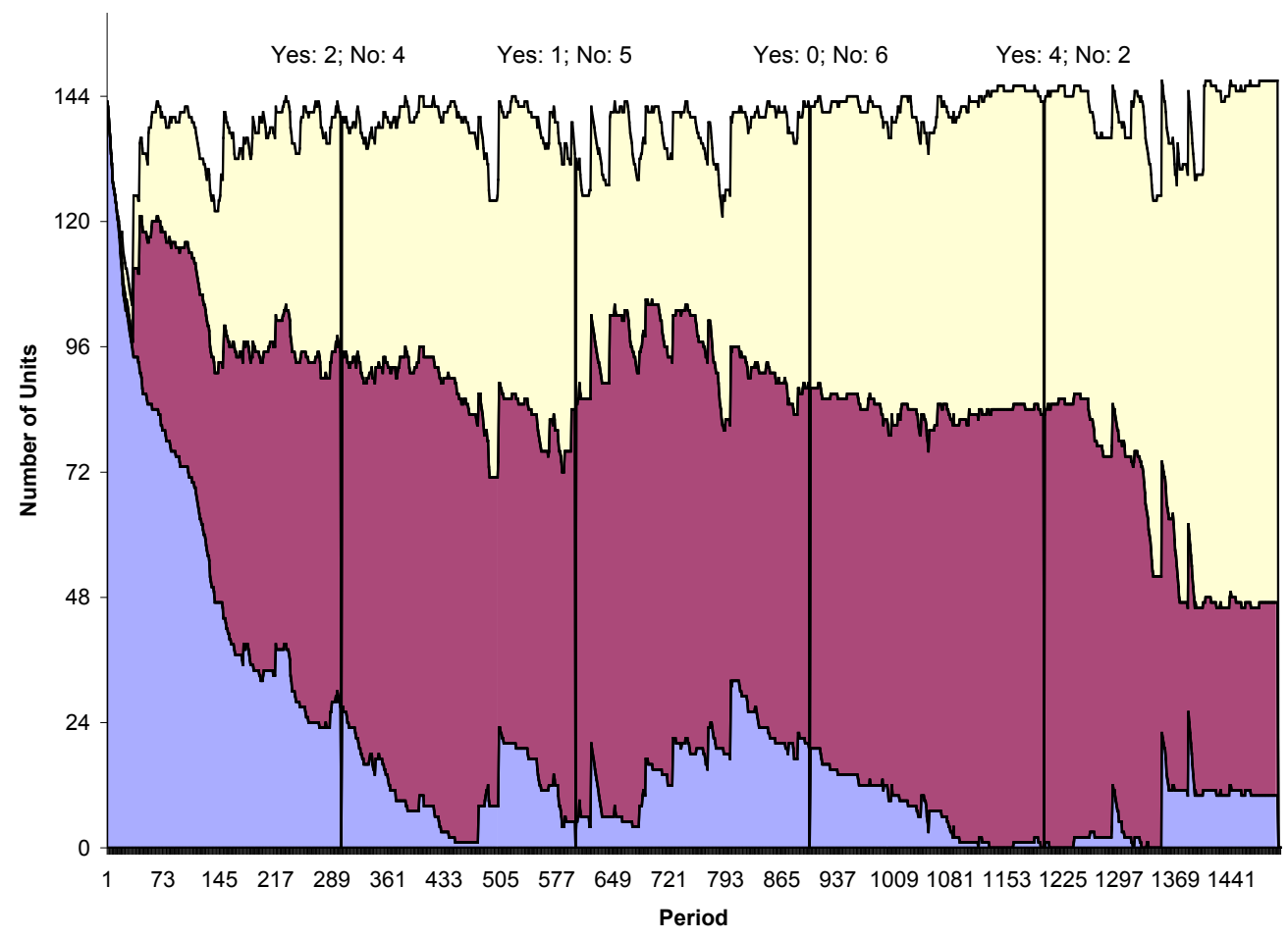

口Defense Units

口 Offense Units

口Earning Units

Efficiency: $13.7 \%$

Persons eliminated: 2

Session 6

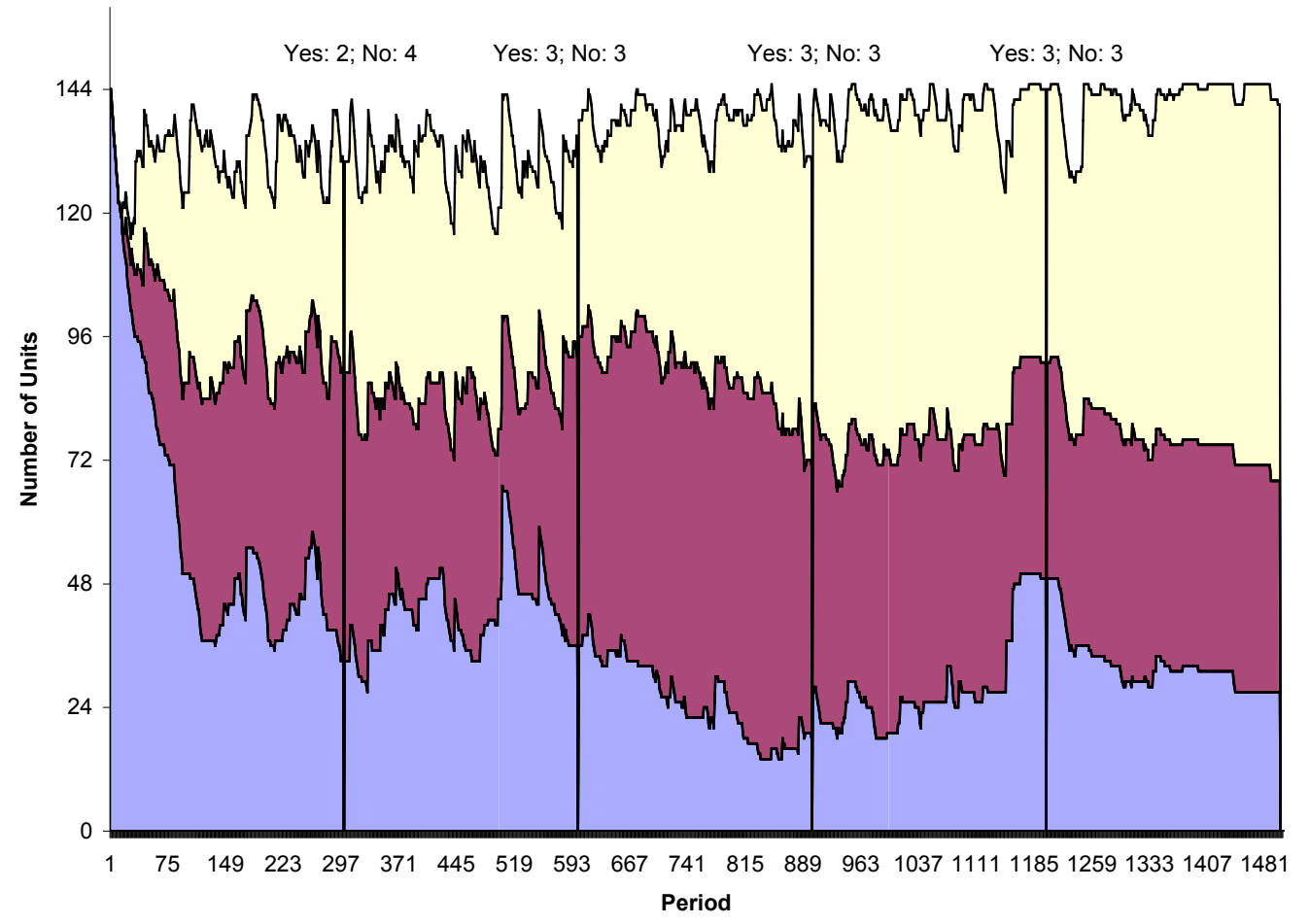

口Defense Units

口 Offense Units

口Earning Units

Efficiency: $26.0 \%$

Persons eliminated: 2

Figure 1c. Allocation of Units 


\section{Session 7}

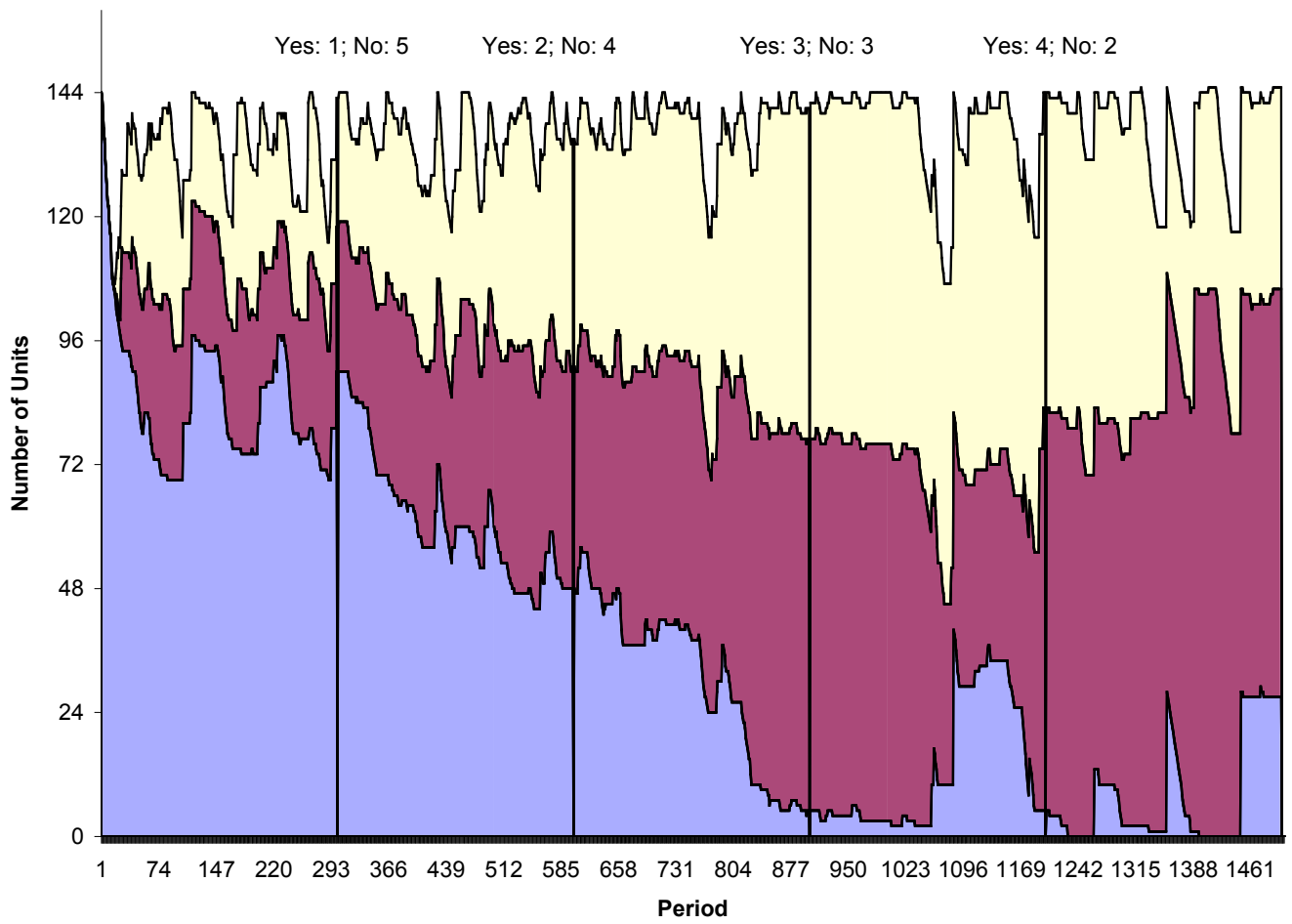

口Defense Units

口Offense Units

口Earning Units

Efficiency: $27.3 \%$

Persons eliminated: 3

Session 8

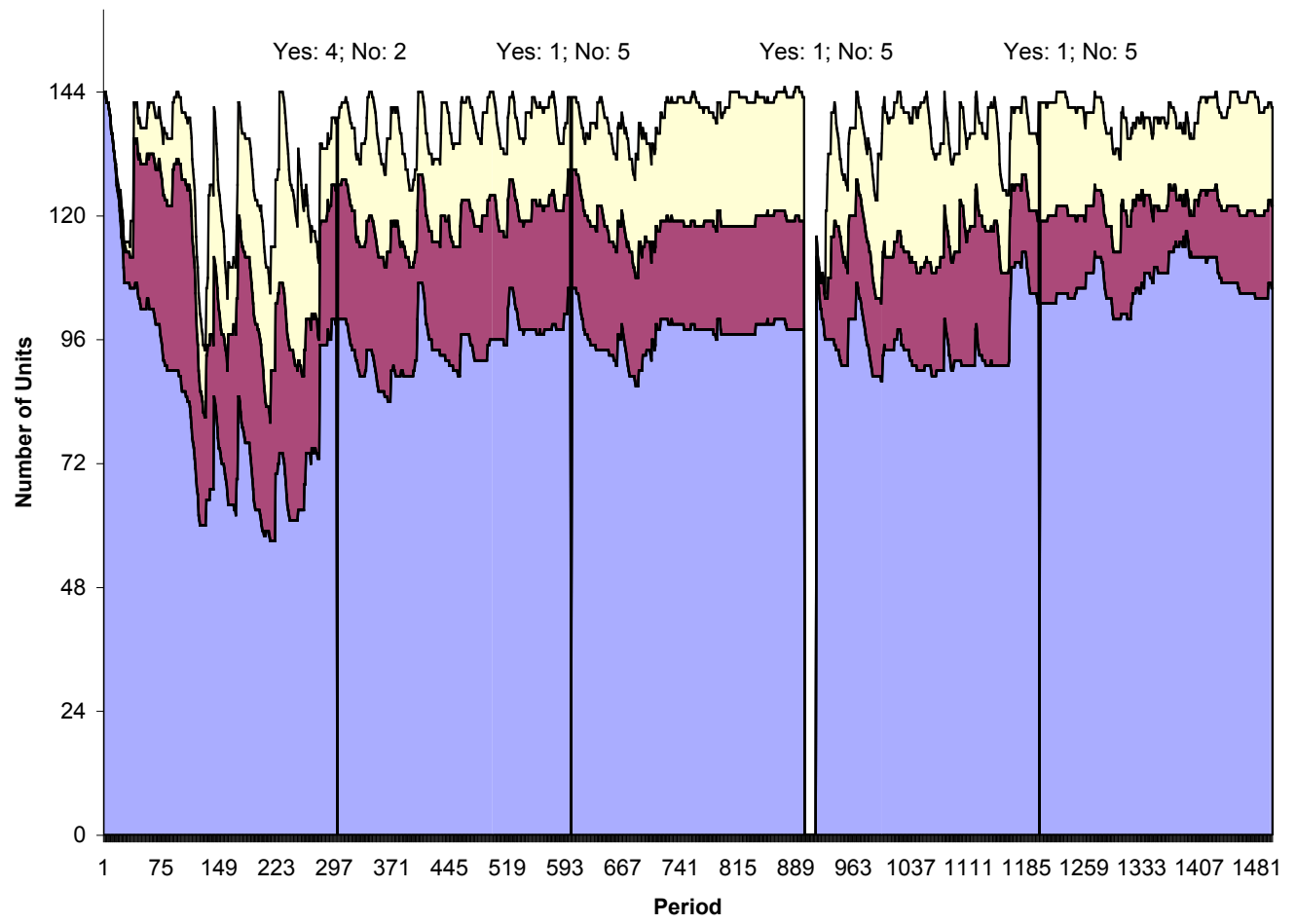

$\square$ Defense Units

口Offense Units

口Earning Units

Efficiency: $66.7 \%$

Persons eliminated: 0

A subject inadvertently hid the experiment window in period 900 . The experiment was reinitialized where it halted and restarted.

Figure 1d. Allocation of Units 
Figure 2: Average Number of Offensive and Defensive Units During the First 5 Minutes

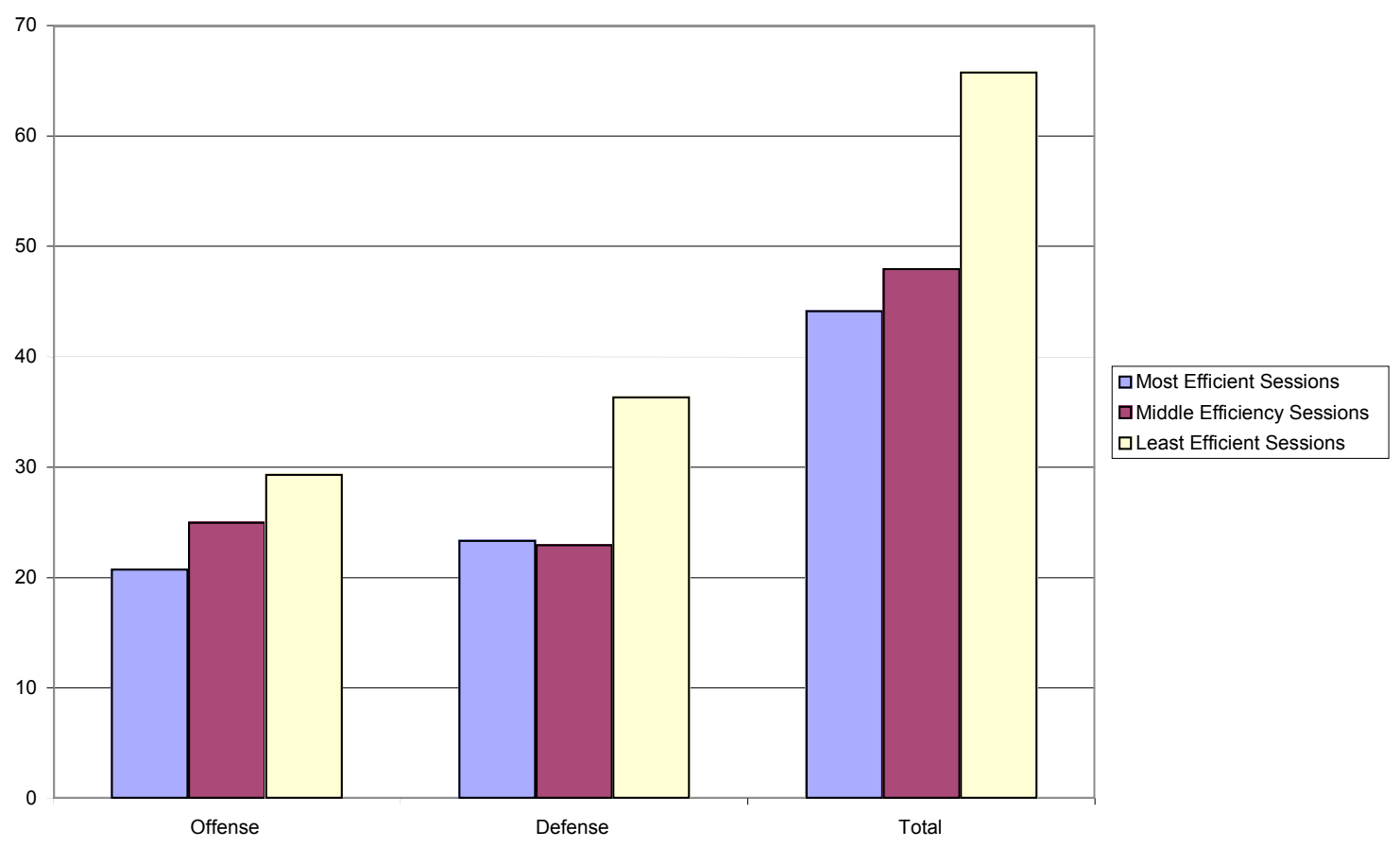

Table 1. Summary Statistics by Session

\begin{tabular}{|c|c|c|c|c|c|c|c|}
\hline Session & $\begin{array}{l}\text { Average } \\
\text { Efficiency }\end{array}$ & $\begin{array}{l}\text { Plunder } \\
\text { Attempts }\end{array}$ & $\begin{array}{l}\text { Votes for } \\
\text { Contract }\end{array}$ & $\begin{array}{c}\text { Persons } \\
\text { Eliminated }\end{array}$ & $\begin{array}{c}\text { Heaviest Relative } \\
\text { Offense }^{\dagger}\end{array}$ & $\begin{array}{c}\text { Average Early } \\
\text { Offense } \\
\end{array}$ & $\begin{array}{c}\text { Average Early } \\
\text { Defense }\end{array}$ \\
\hline 1 & $50.1 \%$ & 272 & 18 & 2 & 0.66 & 32.5 & 26.7 \\
\hline 2 & $41.8 \%$ & 282 & 4 & 2 & 0.64 & 23.6 & 23.2 \\
\hline $3 *$ & $70.6 \%$ & 271 & 4 & 2 & 0.64 & 13.2 & 16.3 \\
\hline 4 & $47.0 \%$ & 249 & 4 & 2 & 0.64 & 26.5 & 22.8 \\
\hline 5 & $13.7 \%$ & 239 & 7 & 2 & 0.75 & 30.9 & 46.7 \\
\hline 6 & $26.0 \%$ & 286 & 11 & 2 & 0.70 & 33.7 & 38.6 \\
\hline 7 & $27.3 \%$ & 226 & 10 & 3 & 0.72 & 23.6 & 24.0 \\
\hline 8 & $66.7 \%$ & 273 & 7 & 0 & 0.71 & 16.7 & 27.1 \\
\hline Average & $42.9 \%$ & 262.3 & 8.1 & 1.9 & 0.68 & 25.1 & 28.2 \\
\hline Max & $100 \%$ & 450 & 24 & 5 & 1.00 & 144 & 144 \\
\hline
\end{tabular}

*Session ended early.

${ }^{\dagger}$ Heaviest Relative Offense $=\frac{o_{\max }}{o_{\max }+\bar{d}_{-i}}$, where $o_{\max }=\max _{i} \sum_{t=1}^{300} o_{i t} / 300$ and $\bar{d}_{-i}=\sum_{j \neq i} \sum_{t=1}^{300} d_{j t} / 300 \times 5, i$ indexes subjects and $t$ periods.

* Average Early Offense $=\frac{\sum_{j=1 t=1}^{6} \sum_{j t}^{300} o{ }_{j t}}{300 \times 6}$

**Average Early Defense $=\frac{\sum_{j=1}^{6} \sum_{t=1}^{300} d t}{300 \times 6}$ 
Table 2. OLS Estimates of Total Yes Votes on Social Contract

\begin{tabular}{lccc} 
& Estimate & St. Error & $p$-value \\
\hline Constant & 6.10 & 2.39 & 0.0173 \\
AvgEff & -2.33 & 1.63 & 0.1666 \\
O/D & -1.08 & 0.81 & 0.1932 \\
PlndAttmpt & -0.03 & 0.04 & 0.5223 \\
$D_{2}$ & -0.72 & 1.02 & 0.4867 \\
$D_{3}$ & -0.47 & 1.09 & 0.6716 \\
$D_{4}$ & -0.34 & 1.01 & 0.7429
\end{tabular}

Table 3. Linear Mixed Effects Estimates of Total Earnings and Total Units at the End of the Session

\begin{tabular}{lcccccr}
\multicolumn{1}{c}{$Y_{i j}=$} & \multicolumn{3}{c}{ TotalEarnings } & \multicolumn{3}{c}{ TotalUnits } \\
& Estimate & St. Error & $p$-value & Estimate & St. Error & $p$-value \\
\hline$\alpha$ & -1.99 & 4.74 & 0.6776 & 10.52 & 14.15 & 0.4620 \\
Endow & 0.50 & 0.16 & 0.0300 & -0.86 & 0.58 & 0.1441 \\
O300* & -0.11 & 0.14 & 0.4367 & 0.09 & 0.48 & 0.8498 \\
D300* & -0.12 & 0.17 & 0.4763 & 1.71 & 0.46 & 0.0007 \\
PlndAttmpt & 0.24 & 0.03 & $<0.0001$ & 0.53 & 0.11 & $<0.0001$ \\
& 48 Obs. & & & 48 Obs. & &
\end{tabular}

* These estimates are robust to using the average number of units of offense or defense in periods prior to the first poll. 

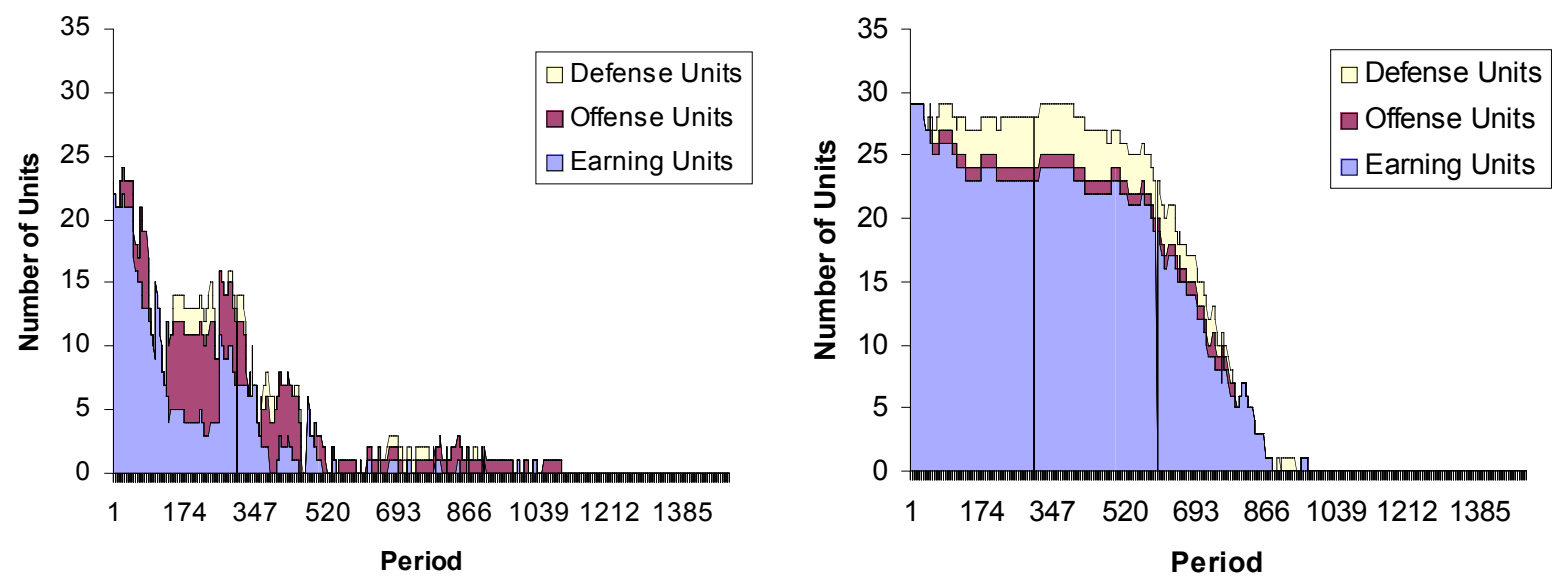

(a) Persons 2 and 5 from Session 3
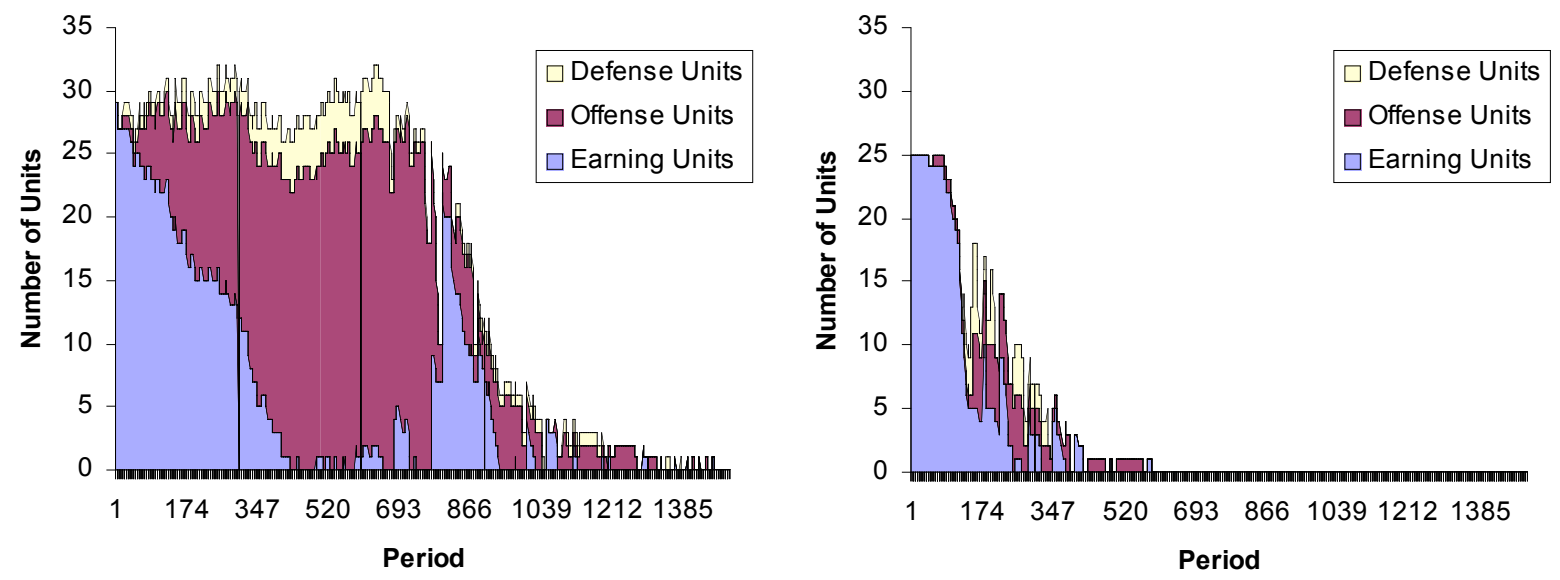

(b) Persons 3 and 4 from Session 5

Figure 3. Allocation of Units by Eliminated Subjects 


\section{References}

Andreoni, James and John Miller. "Rational Cooperation in the Finitely Repeated Prisoner's Dilemma: Experimental Evidence,” Economic Journal 103, 570-585, (1993).

Anderson, Terry L. and P.J. Hill. "American Experiment in Anarcho-Capitalism: The Not So Wild, Wild West," The Journal of Libertarian Studies 3, 9-29, (1979).

Barnett, Randy. The Structure of Liberty. New York, NY.: Oxford University Press, 1998, 2000.

Berg, Joyce, John Dickhaut, and Kevin McCabe. "Trust, Reciprocity, and Social History," Games and Economic Behavior, 10, 122-142. (1995).

Benson, Bruce. "Legal Evolution in Primitive Societies," Journal of Institutional and Theoretical Economics 144, 772-788, (1988).

. The Enterprise of Law: Justice without the State. San Francisco CA.: Pacific Research Institute for Public Policy, 1990.

. To Serve and Protect. New York NY: New York University Press, 1998.

Buchanan, James. The Limits of Liberty. Indianapolis IN.: Liberty Fund, 1975, 2000.

Buchanan, James, and Brennan, Geoffrey. The Reason of Rules. Indianapolis IN: Liberty Fund, $1985,2000$.

Bush, Winston and Mayer, Lawrence. "Some Implications of Anarchy for the Distribution of Property," Journal of Economic Theory 8, 401-12, (1974).

Carter, John and Charles Anderton. "An Experimental Test of a Predator-Prey Model of Appropriation," Journal of Economic Behavior and Organization 45, 83-97, (2001).

Camerer, Colin (2003). Behavioral Game Theory: Experiments in Strategic Interaction, Princeton University Press, Princeton, NJ.

and Keith Weigelt. "Experimental Tests of the Sequential Equilibrium Reputation Model," Econometrica 56, 1-36, (1988).

Caplan, Bryan and Edward Stringham. "Networks, Law, and the Paradox of Cooperation." Review of Austrian Economics 16(4), 309-326, (2003).

Cherry, Todd, Peter Frykblom, and Jason Shogren. "Hardnose the Dictator," American Economic Review 92, 1218-1221, (2002).

Cowen, Tyler. "Law as a Public Good: The Economics of Anarchy." Economics and Philosophy 8, 249-267, (1992). 
Cowen, Tyler and Daniel Sutter. "The Costs of Cooperation," The Review of Austrian Economics 12, 161-173, (1999).

Dawes, Robyn. “Social Dilemmas,” Annual Review of Psychology 31, 169-193, (1980).

Duffy, John, and Minseong Kim. "Anarchy in the Laboratory (and the Role of the State)," Journal of Economic Behavior and Organization, 56, 297-329, (2005).

Durham, Yvonne, Jack Hirshleifer, and Vernon L. Smith. "Do the Rich Get Richer and the Poor Poorer? Experimental Tests of a Model of Power," American Economic Review, 88, 970983, (1998).

Grossman, Herschel, and Minseong Kim. "Predation and Production." In: Garfinkel, M.R., Skaperdas, S. (Eds.), The Political Economy of Conflict and Appropriation. Cambridge University Press, New York, 57-71, (1996).

Friedman, David. "Private Creation and Enforcement of Law -- A Historical Case." Journal of Legal Studies 8(2), 399-415, (1979).

. The Machinery of Freedom. La Salle, IL.: Open Court Publishing Company, $1989,1995$.

. "Law as a Private Good: A Response to Tyler Cowen on the Economics of Anarchy," Economics and Philosophy 10, 319-327, (1994).

Hirshleifer, Jack. "The Paradox of Power," Economics and Politics, 3(3), 177-200, (1991).

. “Anarchy and Its Breakdown," Journal of Political Economy, 103, 26-52, (1995).

Hobbes, Thomas. Leviathan. Cambridge, MA: Cambridge University Press, 1651, 1996.

Hoffman, Elizabeth, Kevin McCabe, Keith Shachat, and Vernon L. Smith. "Preferences, Property Rights and Anonymity in Bargaining Games," Games and Economic Behavior 7, 346-380, (1994).

Hoffman, Elizabeth and Matthew Spitzer. "The Coase Theorem: Some Experimental Tests," Journal of Law and Economics 25, 73-98, (1982). and . "Entitlements, Rights, and Fairness: An Experimental Examination of Subjects Concepts of Distributive Justice,” Journal of Legal Studies 15, 254-297, (1985).

Horan, Richard, Erwin Bulte, and Jason Shogren. "How Trade Saved humanity from Biological Exclusion: An Economic Theory of Neanderthal Extinction." Journal of Economic Behavior and Organization 58, 1-29, (2005). 
Isaac, R. Mark and James Walker. "Group Size Effects in Public Goods Provision: The Voluntary Contribution Mechanism," Quarterly Journal of Economics, 103(1), 179-200, (1988).

Kelley, Harold and Anthony Stahelski. "Social Interaction Basis of Cooperators' and Competitors' Beliefs about Others," Journal of Personality and Social Psychology 16, 66-91, (1970).

Kurrild-Klitgaard, Peter. "Blood, Baath and Beyond: The Constitutional Dilemma of Iraq." Public Choice 119, 13-30, (2004).

McGuire, Martin and Mancur Olson. "The Economics of Autocracy and Majority Rule: The Invisible Hand and the Use of Force," Journal of Economic Literature 34, 72-96, (1996).

Mueller, Dennis. Public Choice III. Cambridge, UK.: Cambridge University Press, 2003.

Muller, Christian. "The Methodology of Contractarianism in Economics." Public Choice 113, 465-483, (2002).

Murphy, Russell. "Crime, Confiscation, and Growth: For and Against Leviathan.” Public Choice 118, 325-339, (2004).

Nozick, Robert. Anarchy, State and Utopia. New York, NY.: Basic Books, 1974.

Olson, Mancur. Power and Prosperity. New York, NY.: Basic Books, 2000.

Powell, Benjamin and Coyne, Christopher. "Do Pessimistic Assumptions Justify Government?" Journal of Libertarian Studies 18(4), 17-37, (2003).

Proudhon, Pierre-Joseph. What is Property? Cambridge, MA.: Cambridge University Press, 1994.

Rothbard, Murray. For a New Liberty. San Francisco, CA.: Fox \& Wilkes, 1973, 1996.

Rummel, R.J. Death by Government. New Brunswick, NJ.: Transaction Publishers, 1994.

Smith, Vernon. "Microeconomic Systems as an Experimental Science," American Economic Review 72(5), 923-955, (1982).

Smith, Vernon. “The Two Faces of Adam Smith,” Southern Economic Journal 65(1), 119, (1998). . Bargaining and Market Behavior. Cambridge, UK.: Cambridge University Press, 2000.

Stringham, Edward. "Market Chosen Law," The Journal of Libertarian Studies 14(1), 53-77, (1999). 
Sutter, Daniel. "Asymmetric Power Relations and Cooperation in Anarchy," Southern Economic Journal 61, 602-613, (1995).

Tullock, Gordon. "The Welfare Costs of Tariffs, Monopolies and Theft," Western Economic Journal 5, 224-32, (1967).

. Explorations in the Theory of Anarchy. Ed. Blacksburg VA.: Center for the Study of Public Choice, 1972.

. The Social Dilemma. Blacksburg VA.: Center for the Study of Public Choice, 1974.

. “Adam Smith and the Prisoners' Dilemma." Quarterly Journal of Economics 100, 1073-1081, (1985).

Voigt, Stefan. "Breaking with the Notion of Social Contract: Constitutions as Based on Spontaneously Arisen Institutions." Constitutional Political Economy 10, 283-300, (1999). 


\section{Appendix 1: Instructions}

<page 1>

This is an experiment in the economics of decision-making. Various research foundations have provided funds for this research. The instructions are simple, and if you understand them, you may earn a considerable amount of money that will be paid to you in $\mathrm{CASH}$ at the end of the experiment. Your earnings will be determined partly by your decisions and partly by the decisions of others. If you have questions at any time while reading the instructions, please raise your hand and a lab monitor will assist you.

This is what your screen will look like in the experiment. In this experiment you are grouped with other people. Each of you is endowed with units of a fictitious good X. This amount of X can be used to generate earnings. In this example, you have 10 units of $\mathrm{X}$, as displayed in the center of your screen. You will earn $\$ 0.0014$ per second for EACH unit of $\mathrm{X}$ in this box. This is equivalent to $\$ 0.08$ per minute for each unit of $\mathrm{X}$.

\section{<page 2>}

Your actual endowment of $\mathrm{X}$ will be determined by your answers to a set of 10 questions. When everyone has finished reading these instructions all of you will be asked the same set of 10 questions. Your score is the number of questions you answered correctly. The scores will be ranked from highest to lowest and ties are decided by giving a higher ranking to the person who finishes the quiz in the shortest amount of time. The higher your ranking, the more X you will receive.

\section{$<$ page 3>}

Units of $X$ can also be used to take units of $X$ from other people, which we will call $X$ for offense. Alternatively, units of $X$ can serve as units of $X$ for defense. If you take a unit of $X$ from someone else, it will be added to your units of $\mathrm{X}$ for earning and taken away from their units of $X$ for earning. One unit of $X$ for earning can be converted into 1 unit(s) of $X$ for offense or defense.

To transfer earnings units to offense/defense units, click on the arrow button. You must wait 20 seconds for the transfer to be completed. At anytime you can transfer offense/defense units back to earning units, but again it will take 20 seconds for the transfer to be completed.

\section{$<$ page 4>}

On the "Take" tab, the taker can try to take a unit from another person, the target by clicking on the "Take from Person \#" button. The taker will be successful depending on how much units for offense the taker has with respect to his target.

Specifically, the probability that the taker is successful is:

Success rate for taker $=($ units of offense $) /($ units of offense + units of defense $)$

For example, if the taker has 1 unit of offense and the taker has 1 unit of defense, the probability that the taker will be successful is $1 /(1+1)$ or $50 \%$. 
If the target has 2 units of defense and taker 1 unit of offense, the taker would have a $33 \%$ chance of being successful. If the target has no units of defense the taker will be successful $100 \%$ of the time. Once a person attempts to take a unit from another, he cannot attempt again for another 20 seconds.

$<$ page 5>

A summary of the information is displayed at the bottom of your screen. You will not be told how long the experiment will last. This is the end of the instructions. If you have any questions, please raise your hand and a monitor will come by to answer them. The experiment will begin when everyone has finished

\section{Appendix 2: Quiz}

\section{General Knowledge Quiz}

Instructions: Below are ten general knowledge questions. Answer the questions to the best of your ability. Each correct answer is worth 1 point, making a total of ten points. There is no penalty for an incorrect answer. When you are finished, raise your hand and someone will pick up the quiz.

1. How many prongs are there on a dinner fork? (4)

2. What color is a crab's blood? (blue)

3. What was the previous name of Thailand? (Siam)

4. Where is the smallest bone in the body? (ear)

5. Which is the only mammal that can't jump? (elephant)

6. Which is the smallest ocean? (Arctic)

7. When did the first man go into space? (1961)

8. What is the capital of Australia? (Canberra)

9. What is the Canadian national anthem? (Oh Canada)

10. What did the 7 dwarves in Snow White do for a job? (miners) 